\title{
Perceptions of Tourists Towards the Role of Stakeholders for Tourism Development
}

\author{
HALIMA BEGUM ${ }^{1 *}$, ER A C ${ }^{1}$, A. S. A. FERDOUS ALAM ${ }^{1}$ and CHAMHURI SIWAR ${ }^{2}$ \\ ${ }^{1}$ Faculty of Social Sciences and Humanities (FSSK), \\ Universiti Kebangsaan Malaysia (UKM), 43600 UKM Bangi, Selangor D E, Malaysia. \\ ${ }^{2}$ Institute for Environment and Development (LESTARI), \\ Universiti Kebangsaan Malaysia (UKM), 43600 UKM Bangi, Selangor D E, Malaysia. \\ Corresponding Author: halima.shilpi@gmail.com
}

http://dx.doi.org/10.12944/CWE.9.3.19

(Received: October 08, 2014; Accepted: November 14, 2014)

\begin{abstract}
This paper studies the role of stakeholders for tourism development in Malaysia based on the perceptions of tourists who come to the Melaka city. Even though the tourists are satisfied by the existing facilities available presently, there are a few shortcomings that need to be addressed such as neglected traditional issues, bureaucratic barriers, definition of sustainable tourism and communication problem with the local communities. The purpose of the study is to find out the roles of public, private and local community stakeholders of the historic city of Melaka for meeting the needs of tourists for tourism development. The findings indicate that the government, private and local community stakeholders have played positive roles for satisfying the demands of the tourists in shaping the development of sustainable tourism in Melaka. The primary data were collected through survey via interviews with 135 respondents based on their responses to a set of questionnaires which looked into the tourists' perceptions in connection to the facilities available for sustainable tourism. The Likert scale data analyzing and reviewing the role of stakeholder's towards perceptions of the tourists. The implication of the study is that majority of the tourists were positively satisfied and receptive towards tourism in Melaka.
\end{abstract}

Key words: Sustainable tourism, Government, Private sector, Local communities.

\section{INTRODUCTION}

The tourism industry is a rapidly growing industry internationally, contributing to economic enhancement as well as generating employment opportunities worldwide. It is one of the most notable service industries in the world ${ }^{1}$. Tourism is contributing significantly to the world's total gross national product (GNP). The World Tourism Organization $^{2}$ (WTO) predicts that the tourism sector will expand by an average of $4.1 \%$ a year over the next two decades, surpassing a total of 1 billion international travellers by the year 2010 , and reaching 1.6 billion by the year 2020. Nevertheless, like other forms of development, tourism can also cause the problems such as social dislocation, loss of cultural heritage, economic dependence and ecological degradation.

In fact, the development of tourism is growing speedily all over the world especially in a developing country like Malaysia. This sector has been selected as the second engine for the nation's growth in developing the country's global competitiveness. Malaysia is a South East Asian country which is divided into two regions known as East and West Malaysia (also known as Peninsular Malaysia). Malaysia is a somewhat up-to-date competitor in global tourism, where in comparison to other counterparts in the Association of South East Asian Nations (ASEAN) made up of ten member countries including Malaysia, Singapore, Thailand, 
Indonesia, Philippines, Brunei, Cambodia, Myanmar, Laos and Vietnam and many others.

The history of tourism development in Malaysia regarding the activity was carried out by private entrepreneurs and multi-national based companies until 1980. At present all these may be viewed as a mixed blessing but they do offer substantial opportunities for countries like Malaysia to utilize. Based on the United Nations World Tourism Organization (UNWTO) tourism towards 2030 study, tourist arrivals are projected to grow at an average of $3.3 \%$ per annum and are expected to reach 1.8 billion in 2030. Malaysia recorded 25.03 million tourist arrivals generating revenue of RM60.6bil in 2013.This industry affects the Malaysian economy positively as it increases foreign exchange earnings and employment opportunities ${ }^{3}$.

Besides, tourism is the main industry contributing to Melaka's economy because of its status as a historical city. It has been inscribed as a World Heritage Site by UNESCO since 7 July 2008. Melaka has also prevailed in its own rank as a tourist destination. In the world, it was ranked 28th out of 45 travel destinations. From 1999 to 2012, a total of 85.2 million tourists visited Melaka with an average increase of nearly $20 \%$ per annum. Recently, $75.7 \%$ of the tourists who visited Melaka are domestic tourists and the remaining $24.3 \%$ is made up of foreign tourists.

The development of the historic city of Melaka is subjected to the policies of the State Government for sustainable tourism and upgrading of 'Melaka International Airport' put Melaka prominently on the global map and a steady growth of foreigners travelling to Melaka for leisure, business and medical treatments can be expected. There is a coastal highway linking Port Dickson to Melaka and improvements have also been carried out on the Ayer Keroh dual carriageway. Moreover, four infrastructure projects were proposed by the state government Budget 2012. They are responsible for the preparation of the general policies, plans and guidelines in enhancing sustainable tourism in Melaka including the Town and Country planning Act, 2001 (Act 172), Melaka Enactment no. 6 of 1988 etc.
However, the authenticity of the historical fabric such as traditional culture and community identity are not respected properly due to sustainable tourism. Most of these developments are of international or modern style, which in some cases have become intrusive in the heritage conservations. Thus, it would be appropriate be looked into, especially in the development of tourist facilities of Melaka which is rich in history and natural beauty. Due to various difficulties such as bureaucratic barriers, historic districts are big challenges for local governments, private sectors and the local community. The aim of this paper is to discuss the implemented policies by the public and private stakeholders of the historic city of Melaka that will help to ensure the future growth of tourism in the city.

Tourism is contributed significantly towards the development processes of many developing nations in terms of foreign exchange earnings, prerequisite of employment and infrastructure as well as generating the regional economic development ${ }^{4,5}$. However, even though tourism has been alleged as the industry of the future, it faces several challenges in this new century, for instance environmental degradation which creates a barrier for tourism development.

According to ${ }^{6}$, "any group or individual who is affected by the achievement of an organization's objectives known as stakeholders" and the organization's stakeholders include owners, customers, competitors, employees, suppliers, governments, local community organizations, special interest groups, environmentalists, media, unions, trade associations, financial community and political groups.

One of the main stakeholders in tourism development is the public sector. However ${ }^{7}$ mentioned that from the economic point of view, if tourism is dominated by the public sector, then it is unlikely to be developed at the most advantageous rate. Hence, the private sector should also play a vital role in managing tourism in attaining the objectives of tourism for development.

Many European private sectors have used the opportunity to set up a successful tourism 
destination by improving town centres by creating pedestrian precincts, establishing park and ride facilities to, developing the city's marketing around a characteristic theme such as cultural or historical attractions and increasing the attractiveness of the built environment ${ }^{8,9}$.

Although some would argue that the secondary elements such as accommodation, shopping, parks and restaurants are the primary force for some tourists to visit a location ${ }^{8,10}$, others disagree and claim that the part of the leisure product comprising the secondary elements are not the primary motivation when travelling to a city. However, those elements like accommodation, shopping, restaurants and many others significantly influence the decision to come to a city or not.

It has been ${ }^{11}$ investigates that public participation in sustainable tourism planning and management is essential because when development and planning do not fit with local aspirations and capacities, resistance and hostility can increase the cost of business.

The Tourist Development Corporation (TDC) plans and coordinates the activities at the national and international levels, and makes recommendations to the government of Malaysia with regard to measures and policies to be adopted ${ }^{12}$. From the term of the Sixth Malaysia $\operatorname{Plan}^{13}$ to the Tenth Malaysian Plan ${ }^{14}$, the tourism sector has been promoted as a vital economic activity contributing to the socio-economic growth of the country in general. A Special Fund was set up by the Federal Government to further support the effort to develop this division. The budget was billed at about RM 534 million, which was nearly $0.3 \%$ of the total national budget.

Melaka city is very well known for its past history. Melaka, located about $150 \mathrm{~km}$ south of Kuala Lumpur, is a historic city of the Straits of Melaka which developed over 500 years of trading and cultural exchanges between East and West in the Straits of Melaka. The influences of Asia and Europe have endowed the town with a specific multicultural heritage that is both tangible and intangible. Due to its location, it was the regional centre of trade for many years, and is a natural attraction for history and cultural enthusiasts. As noted by ${ }^{15}$, Melaka originated from the Malacca Sultanate in the 15th century, and then it went through colonization, beginning with the Portuguese (1511- 1641), followed by the Dutch (1641-1824) before coming under British rule (1824-1957). During the Sultanate period Melaka evolved into an urban, trade oriented society ${ }^{15}$. However, there is no evidence of built structures of the era which have survived perhaps due to the use of semi-permanent materials.

During the Dutch occupation, the wealthier Dutch settlers took over the area west of Melaka River and erected their brick houses in the area noted as Kampong Kling ${ }^{15}$. This was really the most excellent part of the colonial town with a good view of the sea. Melaka has enhanced their products in and about the state, namely the convenience of the transportation hub, good local dining and comfy accommodation. Most tourist attractions are concentrated in its small city centre which encompasses Jonker Walk that houses Melaka's traditional Chinatown which exhibits Peranakan architecture. A Famosa Fort and St. Paul Hill are among the tourist attractions located in Bandar Hilir, the old city area. There are also many shopping centres located nearby including the Melaka Straits Mosque.

There has been a growing body of literature regarding Melaka that addresses tourism as a viable economic option for local community development. However, there is little evidence in the literature that describes the nature of interaction between local communities and tourism development ${ }^{16}$ which is one of the core elements for developing a viable tourism industry in a destination. While the literature recognizes that the inclusion of the local community in tourism development is considerable, there have been some debates about their role.

The community issues associated with tourism development were addressed at the Cairo meeting in $1995^{7}$, with a range of associated issues and approaches being explored at the following meeting in Melaka, Malaysia ${ }^{17}$. However, the local people are neglected in decision making process.

As a development strategy, tourism has gained significance by contributing a substantial earning in Malaysia for both the local and national 
economy. Previous studies did not give high importance to the necessity of training tourist guides and local community for the tourism development and developing their communication skills with the international tourists. In fact, those are common reasons at present for achieving high satisfaction among tourists.

\section{MATERIALS AND METHODS}

This study was carried out survey via interviews In March 2013; based on a set of questionnaires, involving 135 respondents including local, national and international visitors organized by 'The National University of Malaysia' for the Master Conservation Plan of Melaka project in August 2012. Melaka was chosen as the research area because Melaka as mentioned ${ }^{18}$, 'most of the tourists choose Melaka as a family holiday destination because there are a lot of national heritage and historical sites in the state and such as the A-Famosa, Stadhuys and traditional shop houses in the city are still protected by maintaining its aesthetic value, for example, Kampung Morten and batik puppet maintains its culture with dance and traditional music to attract tourists.'

The tourists' level of satisfaction with the role of the stakeholders such as the public, private and local community for sustainable tourism in Melaka are measured by simple statistical tool such as mean and standard deviation. The statistical analysis measures the status of the stakeholder's services for sustainable tourism of Melaka city. The result of this study shows that the tourists are satisfied on those three sectors. The interviews consist of several parts, namely Government and private sector planning, promotions, attractive events, travellers' choice, travellers' opinion, preference, and demographic of the respondents.

Table. 1: Demographic Profile of the Respondents

\begin{tabular}{llllll}
\hline Issues & $\mathbf{1}$ & $\mathbf{2}$ & $\mathbf{3}$ & $\mathbf{4}$ & $\mathbf{5}$ \\
\hline Tourist's & Male & Female & & & \\
gender & $(51.16 \%)$ & $(48.84 \%)$ & & & \\
Tourist's & $11-20$ & $21-30$ & $31-40$ & $41-50$ & $50-<$ \\
age & $(13.33 \%)$ & $(40.54 \%)$ & $(26.67 \%)$ & $(12.65 \%)$ & $(6.81 \%)$ \\
Ethnicity & Malay & Indian & Chinese & Others & \\
& $(58.64 \%)$ & $(7.21 \%)$ & $(14.69 \%)$ & $(19.46 \%)$ & \\
Religion & Islam & Hindu & Buddha & Christian & Others \\
& $(64.9 \%)$ & $(7.21 \%)$ & $(10.61 \%)$ & $(14.42 \%)$ & $(2.86 \%)$ \\
Marital & Married & Single & Single Mothers & Single Fathers & Others \\
Status & $(48.16 \%)$ & $(48.16 \%)$ & $(2.45 \%)$ & $(0.68 \%)$ & $(0.55 \%)$ \\
Occupation & Self Employed & Government & Private & Others & \\
& $(35.24 \%)$ & $(25.85 \%)$ & $(26.94 \%)$ & $(11.97 \%)$ & \\
Income P/M & Below 1000 & $1001-1500$ & $1501-2000$ & $2001-2500$ & above 2501 \\
(RM) & $(42.04 \%)$ & $(8.57 \%)$ & $(14.42 \%)$ & $(6.8 \%)$ & $(28.16 \%)$ \\
Level of & Diploma/Degree & Primary school & High school & Not in school & Others \\
Education & $-61.91 \%$ & $-14.15 \%$ & $-20.68 \%$ & $-1.22 \%$ & $-2.04 \%$ \\
Tourist's & International & Malaysian & Others & & \\
& & & & & \\
nationality & $(17.41 \%)$ & $(74.83 \%)$ & $(7.78 \%)$ & & $8-<$ \\
No. of & Below 2 & $3-4$ & $5-6$ & $7(8.44 \%)$ & $(6.11 \%)$ \\
Households & $(24.22 \%)$ & $(33.47 \%)$ & $(27.76 \%)$ & & \\
Category of & Local & Visitors & Tourist* & Others & \\
travellers & $(19.32 \%)$ & $(29.93 \%)$ & $(50.48 \%)$ & $(0.27 \%)$ & \\
& & & & & \\
\hline Source: Prim) & & & & \\
& & & & \\
\end{tabular}

Source: Primary survey from Melaka 2013

Note: * Those who stayed for at least 1 night are treated as tourist 


\section{RESULTS AND DISCUSSION}

The study involved 135 respondents comprising local, international tourists and national visitors. Local respondents are those visitors who came from Melaka, while national visitors are those who came from several cities of Malaysia except Melaka, and international visitors are those who came from other countries such as Indonesia, Brunei, Singapore and many others.

The demographic data illustrate the background of the respondents (Table 1 ). It portrays the percentages of the local, national and international visitor-respondents to Melaka. The discussion of the gathered data from the field research is presented based on three categories: government, private sector and local community. The table has been prepared based on the questionnaire conducted in Melaka. The number of male respondents $(51.16 \%)$ is more than the number of female respondents (48.84\%); and young visitors, aged between 21 to 30 years old $(40.54 \%)$, were highly keen to visit the tourist sites. In addition, the majority of the tourists are Malays (58.64\%). Among the despondence only $17 \%$ are foreign tourists, rest of the national visitors, most of them from Melaka which were about $17 \%$, but the others came from Selangor (12.38\%), Kuala Lumpur (10.48\%), Johor Baru (8.57\%), Negeri Sembilan (4.22\%), Kelantan (4.22\%), Kedah (3.53\%), Pulau Pinang (3.4\%), Perak (2.86\%), Sabah (2.58\%), Terengganu (2.04\%), Pahang (1.49\%), Sarawak (1.22\%), Perlis $(0.68 \%)$, and others $(7.76 \%)$ respectively. The majority of the respondents' religion is Islam (64.9\%). In addition, the percentage of single and married respondents in the interviews is the same which is $48.16 \%$ for both the categories.

The majority of the respondents are selfemployed, accounting to almost $35.24 \%$. However, the percentage of those reporting income below 1000 Ringgit Malaysia per month is high (42.04\%). Moreover, according to the level of education, most

Table. 2: Tourists' Perceptions on the role of the Public Sector

\begin{tabular}{lccccccc}
\hline Issues & $\mathbf{1}$ & $\mathbf{2}$ & $\mathbf{3}$ & $\mathbf{4}$ & $\mathbf{5}$ & Mean(\%) & SD(\%) \\
\hline $\begin{array}{l}\text { Govt. current planning } \\
\text { idea(taken from private sector) }\end{array}$ & $0.27 \%$ & $1.77 \%$ & $25.71 \%$ & $47.07 \%$ & $20.14 \%$ & 3.77 & 0.78 \\
More Promotional Facilities & $0.14 \%$ & 3.27 & $23.81 \%$ & $51.43 \%$ & $21.36 \%$ & 3.91 & 0.76 \\
More Attractive Events & $0.27 \%$ & $4.49 \%$ & $28.30 \%$ & $48.16 \%$ & $18.78 \%$ & 3.80 & 0.80 \\
Infrastructure facilities & $0.14 \%$ & $2.86 \%$ & $28.16 \%$ & $52.38 \%$ & $16.46 \%$ & 3.82 & 0.78 \\
Govt. Funding for restoration & $0.27 \%$ & $5.71 \%$ & $31.56 \%$ & $47.21 \%$ & $15.24 \%$ & 3.71 & 0.80 \\
Availability of Public transport & $0.95 \%$ & $6.12 \%$ & $28.57 \%$ & $47.07 \%$ & $17.28 \%$ & 3.74 & 0.85 \\
\hline
\end{tabular}

Source: Primary survey from Melaka 2013

Note: $1=$ Very Unsatisfied; $2=$ Unsatisfied; $3=$ Neutral, $4=$ Satisfied; $5=$ Very Satisfied

Table. 3: Tourists' Perceptions on the role of the Private Sector

\begin{tabular}{lccccccc}
\hline Issues & $\mathbf{1}$ & $\mathbf{2}$ & $\mathbf{3}$ & $\mathbf{4}$ & $\mathbf{5}$ & \multicolumn{2}{c}{ Mean(\%) } \\
& & & & & & & \\
\hline Accommodation services industry & $0.41 \%$ & $2.99 \%$ & $24.63 \%$ & $53.47 \%$ & $18.50 \%$ & 3.87 & 0.76 \\
Availability of transport services & $1.22 \%$ & $6.12 \%$ & $30.75 \%$ & $47.48 \%$ & $14.42 \%$ & 3.68 & 0.84 \\
Availability of food services & $0.14 \%$ & $3.81 \%$ & $27.62 \%$ & $50.88 \%$ & $17.55 \%$ & 3.82 & 0.76 \\
Job opportunities & $1.09 \%$ & $5.85 \%$ & $31.29 \%$ & $44.22 \%$ & $17.14 \%$ & 3.71 & 0.86 \\
Organization's Consciousness & $0.27 \%$ & $3.27 \%$ & $30.34 \%$ & $49.66 \%$ & $16.46 \%$ & 3.81 & 0.76
\end{tabular}

about environment

Source: Primary survey from Melaka 2013

Note: $1=$ Very Unsatisfied; $2=$ Unsatisfied; $3=$ Neutral, $4=$ Satisfied; $5=$ Very Satisfied 
of the respondents had completed either their degree or diploma $(61.91 \%)$. On the other hand, number of household between 3 to $4(33.47 \%)$ is the highest percentage. The percentage of tourists is high because many stayed for at least one night in Melaka because of their satisfaction with the facilities provided as well as their enjoyment of travelling in Melaka.

\section{Public sector:}

Table 2 displays the role of the public sector for s tourism development in Melaka. The government plays an important role in the provision of tourism development in terms of planning, promotions, development projects, events, infrastructure, funding, transport and many others. The result of the study indicates that most of the tourists are satisfied with provided government facilities. At first, it is observed by $52.38 \%$ respondents that more tourists were satisfied because of their infrastructure facilities. In fact, the private sector helped in the planning of tourism development by giving their valuable ideas to the public sector. The highest mean value 3.91 and $51.43 \%$ of the travellers are showing satisfaction because of the Government's promotional activities for tourist attractions. To support this, the campaign ${ }^{19}$ were re launched in February 17, 2004 until the end of 2005.

However, Only $0.14 \%$ are dissatisfied, i.e., it may be because of racism, religious or safety issue at the time the tourists selected the events of attraction, infrastructure facilities as sufficient and satisfactory level as mention by the respondents. Although several types of attractive events have been conducted for the growing number of tourists for making tourists charmed though their events as determined by the satisfactory level opined by the respondents (48.16\%). Moreover, $47.21 \%$ of the respondents opined that the supplied financial and capital fund is really sufficient for renovations and restoration. On the basis of the Government's current, short term and long term planning for tourism development, most of the visitors are satisfied $(47.07 \%)$

Finally, the Government provides several types of vehicles for national and international tourists such as taxi cabs, buses, rickshaws and many others and because of that transportation is easily available and going around Melaka city is quite easy. Only $7.07 \%$ of the visitors felt dissatisfied because of the unavailability of public transportation. The statistical calculations by mean and standard deviation also show the same result i.e. in the satisfactory level. It is recommended that the public sector works harder at implementing efficient planning so that the highest level can be achieved for tourist satisfaction. This would allow the stakeholders' role for tourism development to reach the highest rate of satisfaction where respondents

Table. 4: Tourists' Perceptions on the role of Local Communities

\begin{tabular}{|c|c|c|c|c|c|c|c|}
\hline Issues & 1 & 2 & 3 & 4 & 5 & Mean (\%) & $\mathrm{SD}(\%)$ \\
\hline $\begin{array}{l}\text { Local people Sharing } \\
\text { knowledge and information }\end{array}$ & $3(0.41 \%)$ & $2.86 \%$ & $25.85 \%$ & $51.97 \%$ & $18.91 \%$ & 3.88 & 0.76 \\
\hline Local community's fund & $0.82 \%$ & $3.67 \%$ & $29.93 \%$ & $47.76 \%$ & $17.40 \%$ & 3.78 & 0.81 \\
\hline Involvement of local tourists & $0.54 \%$ & $5.71 \%$ & $27.35 \%$ & $49.52 \%$ & $16.87 \%$ & 3.77 & 0.82 \\
\hline Cleanliness of the local people & $0.41 \%$ & $4.35 \%$ & $31.43 \%$ & $46.67 \%$ & $17.14 \%$ & 3.76 & 0.80 \\
\hline Local tour guide & $0.41 \%$ & $3.81 \%$ & $28.98 \%$ & $34.58 \%$ & $18.91 \%$ & 3.82 & 0.79 \\
\hline $\begin{array}{l}\text { Local people value of Protection } \\
\text { and preservation of culture }\end{array}$ & $0.54 \%$ & $4.08 \%$ & $27.21 \%$ & $47.35 \%$ & $20.82 \%$ & 3.84 & 0.82 \\
\hline $\begin{array}{l}\text { Local people feedback } \\
\text { and recommendation }\end{array}$ & $0.68 \%$ & $4.63 \%$ & $29.80 \%$ & $47.76 \%$ & $2.18 \%$ & 3.76 & 0.81 \\
\hline Local travel agency services & $0.54 \%$ & $3.54 \%$ & $29.93 \%$ & $49.12 \%$ & $16.87 \%$ & 3.78 & 0.78 \\
\hline The quality of services & $1.09 \%$ & $4.22 \%$ & $28.03 \%$ & $49.80 \%$ & $16.87 \%$ & 3.77 & 0.18 \\
\hline
\end{tabular}

Source: Primary survey from Melaka 2013

Note: $1=$ Very Unsatisfied; $2=$ Unsatisfied; $3=$ Neutral, $4=$ Satisfied; $5=$ Very Satisfied 
really feel safe, secure and charmed by the facilities provided.

\section{Private sector:}

The data in Table 3 shows the percentages of different areas in terms of the role or services of stakeholders in the private sector as well as analysis of the respondents' satisfaction or dissatisfaction through the facilities provided. The public and private sector are both very conscious of the need to provide attractive facilities to the tourists to increase the local and national earnings in Melaka. The highest mean value 3.87 and $53.47 \%$ respondents mentioned that they were satisfied staying in the hotels or restaurants as can be seen by availability of accommodation services. Therefore, the accommodation services industry in Melaka is enough to provide the comfort needed for tourists. This is assertion with the previous studies that the customer's satisfaction is important for successful destination marketing ${ }^{20}$. The $50.88 \%$ respondents mentioned satisfaction regarding food availability too. The different types of food shops are readily available for all type of tourists. However, 0.14\% expressed extreme dissatisfaction in terms of the food services. Consequently, tourism development is creating satisfactory job opportunities in Melaka, reported at $44.22 \%$, which could be probably due to the growing tourism industry in Melaka. This decreases the unemployment problem, not only in Melaka but also in Malaysia in general. Even though the price of public transportation services is in the satisfactory level, some tourists do face serious problem (1.22\%).

The government sector is continuously monitoring the private sector through implementing laws. Tourists are also satisfied by $16.46 \%$ respondents. Various organizations involved in the tourism sector are concerned with the environment, as outlined in the environmental laws that have been enacted by the government. The mean and standard deviation value carried the same results on the basis of computations that are at the satisfactory level. Although their continuous monitoring is improving earning and creating lots of opportunities worldwide, it is recommended that the private sector moves further by having efficient planning and promoting the facilities to achieve the highest level of satisfaction.
Local community:

The Table 4 shows the percentages of different areas of the role of the stakeholders in the community sector as well as analysis of the respondents' satisfaction or dissatisfaction through the facilities provided. The role of the stakeholder's services for tourism development for the community sector is also in the satisfactory level. The local community are eagerly helping the tourists by giving their personal services to promote their heritage city of Melaka. Among the respondents, the highest mean value that is 3.87 and $51.97 \%$ mentioned that the local community shares their knowledge and information regarding several beautiful locations such as the World Heritage Site and other facilities regarding infrastructure with the visitors who arrived in Melaka. Besides, previous literature review also supports these. There is an existing literature that these policies consist of a better commitment towards the communities for tourism development and serve as hosts to the tourists ${ }^{21}$, increased respect for the places that accept and receive tourists ${ }^{5}$ and larger responsibilities towards the tourist's themselves ${ }^{22}$.

A small minority of respondents, i.e. only $0.41 \%$ of the tourists, is of negative opinion about cleanliness and local guides. In order to generate more recognition of Melaka, the local people must always ensure the environment is properly maintained and clean. Furthermore, most workers / tour guides are local residents. The agency services and their communication with the tourists are really in satisfactory level (49.12\%) through tourists perceptions. Therefore, the projects are really successful through the help of the government and also the local community which is at $47.76 \%$. Feedback and recommendation from the locals have also undertaken into consideration for tourism development in the city constantly.

The mean data results are greater than the standard deviation, i.e., the result indicates good satisfactory comments among the tourists. Finally, tourists as well as local residents show their satisfaction with the overall quality of services provided. However, further improvements are needed to attain the highest level of satisfaction among the tourists. As mentioned, the local people or community is the basic element in modern tourism as they are the central point for the 
supply of accommodation, catering, information, transport facilities and services. Their local natural environment, buildings and institutions, their people, culture and history, all form the core elements of what the tourists come to see, whether as towns, villages or cities. Every local community has tourism at one level or the other hand is affected by the growth and development of the industry ${ }^{23}$. Involvement of local people is the equitable distribution of the benefits in the tourism development process.

Tourism is one of the major sources of earnings in the world. Malaysia is one of the leading countries in this sector whereas Melaka city is earning huge amounts of money every year through tourism. To achieve this position, the government is not only establishing current and long term plans but also hiring ideas from the private sectors for tourism development. The mean and standard deviation show that tourism in Melaka is encouraging and it will reach peak level. However, it needs further improvement and better planning. More significantly, successful development projects would generate a catalytic process in the surrounding communities. Through more interactive approaches, all these positive developments and outcomes encourage up to date and modern supporting facilities for the respondents or tourists, which would lead towards world recognition and acknowledgement. Subsequently, encouraging the involvement of the private sector and public-private partnership initiatives could help in safeguarding visitors and maintaining the infrastructure facilities, fostering best practice awards for local, national and regional or international tourist. But one of the main problems is the local community. The Government is not giving more priority to the local residents. Moreover, local people have communication problems. They lack knowledge of the English language which is an international language. The local people need language training to achieve sustainable tourism.
It has been recommended that National modern tourism laws and policies should be established. This public and private policy should consider the long term goals of urban planning which results in the overall development of the towns and generates profits for the different groups. More employment in the local communities is needed to establish new tourist industries and restoration work. Accordingly, all necessary training and support should be given to the tour guides by the government and international agencies to make them able to effectively guide the international tourists. Despite these achievements, several issues needed to be addressed, including the need of developing sustainable tourism, ecotourism, nature tourism, cultural tourism, service tourism and other potential tourism products to attract tourists to Melaka. Accordingly, the role of public and private stakeholders, community benefit sharing opportunities, attracting foreign investment and region based tourism development are necessary to enhance the tourism sector in Malaysia. Lastly, future studies require a combination of numerous methodological approaches such as the applications of structural modelling (SEM) or multi methods as well as research tools that combine quantitative and qualitative methods.

\section{ACKNOWLEDGEMENTS}

Financial assistance provided by the under research grant FRGS/1/2013/SS008/UKM/02/1 led by Prof. Dr. Er Ah Choy, Faculty of Social Sciences and Humanities (FSSK), Universiti Kebangsaan Malaysia (UKM), and research grant DPP-2014-105, led by Prof. Dr. Joy Jacqueline Pereira, Southeast Asia Disaster Prevention Research Institute (SEADPRI), Universiti Kebangsaan Malaysia (UKM) are gratefully acknowledged. 


\section{REFERENCES}

1. Schumacher, H. J. Let's Talk Europe: Ecotourism. Business World. p. S1/6, (2007).

2. United Nations World Tourism Organization (UNWTO). Tourism: 2020 Vision, (1999).

3. M A H Bhuiyan, C Siwar, S M Ismail, R Islam, D Ehsan. Potentials of Islamic Tourism: A case Study of Malaysia on East Coast Economic Region. Australian Journal of Basic and Applied Sciences, 5(6), 1333-1340, (2011).

4. Rigg, J.Southeast Asia-the Human Landscape of Modernisation and Development, New York: Routledge, (2003).

5. Meethan, K. Tourism in Global Society: Place, Culture and Consumption, New York: Palgrave, (2001).

6. Freeman, R.E. Strategic management: A stakeholder approach. Boston: Pitman, (1984).

7. Cooper, C., Fletcher, J., Gilbert, D., \& Wanhill, S. Tourism principles and practice. Harlow: Pearson, (1993).

8. Schofield, P. Urban tourism and small businesses. In N. Douglas, N. Douglas, \& R. Derret (Eds.), Special interest tourism: context and cases (pp. 432-450). Brisbane: John Wiley and Sons, (2001).

9. Warren, J. A. N., \& Taylor, C. N. Developing urban tourism in New Zealand. Wellington: Centre for Research, Evaluation and Social Assessment, (2003).

10. Shaw, G. \& Williams, A. M. Critical issues in tourism: A geographical perspective. Oxford, UK: Blackwell, (1994).

11. Keogh.'Issues of Tourism and Conservation in Sauraha', Report of University Expedition to Nepal. Manchester: Guru Publishers' 176189, (1990).

12. Tourist Development Corporation (TDC). Malaysia Tourism News, (1975).
13. Government of Malaysia. Sixth Malaysia Plan 1991-1995. Economic Planning Unit, Prime Minister's Department, Malaysia, (1991).

14. Malaysia. Tenth Malaysia Plan 2011-2015. Economic Planning Unit, Economic Planning Unit, Prime Minister's Department, Malaysia, (2011).

15. Lim, Huck hin and Fernando, J. Melaka: Voices from the Street Malaysia: Lim Huck Chin, (2006).

16. Aref F, Gill SS, Farshid A. Tourism development in local communities: As a community development approach. Journal of American Science, : 155 - 161, (2010).

17. Pearce and R.W. Butler (eds), Contemporary Issues in Tourism Development, London: Routledge, pp.52-64, (1999).

18. Er, A. C. Pembangunan Pelancongan Lestari Di Melaka: Perspektif Pelancong. Geografia: Malaysian Journal of Society and Space 9(3): 12-23, (2013).

19. Cuti-Cuti. Utusan Malaysia, 1-2, February 18, (2004).

20. Kozak, M. and Rimmimgton, M. Tourist Satisfaction with Mallorca, Spain, as an off season holiday destination. Journal of Travel Research 38: 260-269, (2000).

21. Tosun, C. and Timothy D. Arguments for community participation in the tourismprocess, Journal of Tourism Studies, 14(2): 2-12, (2003).

22. Winter, T. The modernities of heritage and tourism: interpretations of an Asian future, Journal of Heritage Tourism, 4(2): 105-115, (2008).

23. Godfrey K, Clarke J. Tourism Development handbook: A Practical Approach to Planning and Marketing. London: Cengage Learning EMEA, (2000). 